\title{
MAPEAMENTO DA ACESSIBILIDADE DO PORTADOR DE LIMITAÇÃO FÍSICA A SERVIÇOS BÁSICOS DE SAÚDE
}

\author{
Demarcation of the accessibility of \\ the handicapped to a basic health services \\ Demarcación del acceso del portador de \\ limitación física a los servicios básicos de salud
}

Luciana Rodrigues Vasconcelos

Lorita Marlena Freitag Pagliuca

\begin{abstract}
Resumo
Reconhecendo os direitos dos portadores de limitação física no quesito acessibilidade, objetiva-se mapear as barreiras arquitetônicas de acesso aos serviços básicos de saúde. Estudo exploratório-descritivo, com amostra intencional de 12 unidades em município de médio porte. Coleta de dados por formulário tipo cheque-lista. Foi observado que a arquitetura externa dificulta ou impossibilita o acesso, pois as calçadas contêm obstáculos, ausência de rebaixamento de meio-fio, sinalização em pontos estratégicos e de estacionamento demarcado. Em contrapartida, a maioria das unidades possui rampas de acesso com corrimão e corredores com largura adequada. Balcões, mesas, assentos, telefones, bebedouros estão predominantemente a uma altura superior à preconizada, e os banheiros não oferecem espaço suficiente para transposição de cadeira de rodas; nestes não há barras horizontais, e a maioria das peças sanitárias está a uma altura inadequada. Tais barreiras são obstáculos para o usufruto, por parte dos portadores de limitação física, dos equipamentos de saúde disponibilizados à sociedade.
\end{abstract}

Palavras-chave: Estruturas de acesso. Pessoas Portadoras de Deficiência. Acesso aos Serviços de Saúde. Política de Saúde.

\begin{abstract}
Recognizing the rights of the handicapped concerning accessibility, this paper aims at verifying the architectonic barriers related to the access to basic health services. This is an exploratory and descriptive study with an intentional sample of 12 units in a medium size municipality. Data were collected through a checklist form. It was noticed that external architecture hampers or blocks access, for sidewalks have obstacles, there are no leveled passages, signs in strategic points or in parking areas. Conversely, most units have access ramps with handrail and proper-width corridors. Front-desks, desks, seats, telephones, drinking fountain, are mostly higher than the appropriate and restrooms do not offer enough space for transposition from the wheel chair; there are not horizontal bars and most of the toilets are in an improper height. Such barriers are obstacles for the use by the handicapped of health equipment available for society.
\end{abstract}

\begin{abstract}
Resumen
Al reconocer los derechos de los portadores de deficiencias desde el punto de vista de posibilidad de acceso se estipula demarcar las barreras arquitectónicas de acceso a los servicios básicos de salud. Es un estudio de índole descriptivo y de exploración, con muestra intencional de 12 unidades en municipios de medio porte. Recogida de datos medio de formularios del tipo chequeo-lista. Se observó que la estructura externa dificulta o imposibilita el acceso, ya que las aceras poseen obstáculos, hay ausencia de desnivel del cordón de la acera, señalización en puntos clave y parqueamiento demarcado. Como contrapartida, la mayoría de las unidades poseen rampas de acceso con pasamano y corredores de ancho adecuado. Mostradores, mesas, asientos, teléfonos, bebederos están a una altura predominadamente superior a la preconizada y los baños no ofrecen suficiente espacio para moverse en sillas de ruedas; en estes no hay barras horizontales y la mayoría de las piezas sanitarias se encuentra a una altura inadecuada. Dichas barreras son obstáculos para el usufructo, por parte de los deficientes físicos, de los equipamientos de salud a disposición de la sociedad.
\end{abstract}

Keywords: Architectural accessibility. Disabled Persons. Health Services Accessibilty. Health Policy.
Palabras clave: Estructuras de Acceso. Personas con Discapacidad. Accesibilidad a los Servicios de Salud. Política de Salud. 


\section{INTRODUÇÃO}

As pessoas com deficiência possuem limitações físicas, sensoriais ou mentais que muitas vezes geram dificuldades e impossibilidades de execução de atividades comuns às outras pessoas, resultando na dificuldade de deslocamento de um lugar a outro. Diante disto, impõe-se a utilização de equipamentos que permitam melhor convivio, dadas as barreiras do ambiente físico. A Constituição Federal de 1988 dispensou tratamento diferenciado às pessoas com deficiências. É preciso, porém, assegurar a estes sujeitos o exercício efetivo da cidadania e da convivência social, mediante o exercício do direito de liberdade e autonomia para ir e vir. A Constituição garante o direito ao trabalho, à educação, à saúde, ao lazer. É, pois, necessário garantir o deslocamento decorrente dessas atividades ${ }^{1}$.

Cerca de $15 \%$ da população brasileira apresenta algum tipo de deficiência. Esse percentual corresponde aproximadamente a 25 milhões de pessoas ${ }^{2}$. De cada seis pessoas (100\%), uma (15\%) tem algum tipo de deficiência. Aparentemente, esta afirmação é duvidosa, pois não vemos essas pessoas circulando nas ruas e na sociedade. Como observado, a desatenção dos setores públicos na questão da acessibilidade dos centros urbanos exclui cerca de $70 \%$ desses do contexto social ${ }^{2}$. Mencionado expressivo contingente populacional aumenta a necessidade de promover diagnóstico deste segmento da população brasileira e contribuir para ações de inclusão social.

Conforme enuncia a Organização Mundial de Saúde (OMS), pessoa com deficiência é aquela que porta um comprometimento físico, sensorial ou mental, o qual Ihe acarreta limitação e a coloca em situação de desvantagem em relação à categoria das pessoas consideradas "normais"3. Muitos deficientes físicos enfrentam dificuldades para se locomover. Diante de tais dificuldades, eles utilizam muletas ou cadeiras de rodas. Para esses portadores de limitação, o simples ato de sair de casa significa um desafio, sobretudo porque as cidades não dispõem de estrutura adequada para deficientes. De modo geral, por inexistir o devido planejamento, a conduta predominante é adaptar um edifício já construído e não considerar essas dificuldades ainda naquela fase.

Conceituar com clareza palavras ou expressões para designar determinadas situações ou características contribui para direcionar as ações de intervenção. A palavra deficiência freqüentemente se associa a incapacidade e desvantagem. Deficiência é entendida como perda ou anormalidade de estrutura ou função psicológica, fisiológica ou anatômica, temporária ou permanente, e incapacidade, como restrição da habilidade para desempenhar atividade considerada normal para o ser humano, decorrente de uma deficiência. Desvantagem é entendida como prejuízo resultante de uma deficiência ou incapacidade, que impede o desempenho de papéis ${ }^{4}$. Pode acrescentar-se a palavra limitação, decorrente ou não de uma deficiência, mas freqüentemente associada a situações de saúde-doença, de fase do ciclo vital, de características físicas. A aceitação desta denominação amplia em muito a visibilidade do contingente de pessoas que se vêem permanente ou temporariamente limitadas no seu acesso aos serviços básicos de saúde.

No referente ao deslocamento aos serviços de saúde, as dificuldades vivenciadas por estas pessoas são reconhecidas pelo próprio Ministério da Saúde quando este confirma os dados da OMS, segundo os quais, dos $10 \%$ das pessoas deficientes, apenas $2 \%$ recebem assistência ${ }^{3}$. A priori, a Saúde Pública tem por enunciação o desenvolvimento de programas de prevenção e controle das doenças. Com base nesse princípio, espera-se melhor qualidade de vida mediante a superação de fatores que lesam a saúde e a resolução dos problemas que afetam o meio ambiente. Contudo, os serviços de saúde ainda desempenham um papel secundário em relação à meta proposta pela OMS de oferecer "Saúde para todos no ano 2000" 5.

Quando a arquitetura citadina apresenta obstáculos ao deslocamento das pessoas, impõe a segregação de um estrato específico da sociedade: idosos, obesos, deficientes físicos e sensitivos. As dificuldades para a pessoa com limitação física acessar os serviços públicos de saúde são percebidas particularmente no trajeto casainstituição assistencial. Portanto, a remoção de barreiras arquitetônicas representa um importante passo para a integração dos deficientes na atividade humana. Com esta finalidade, determinados municípios desenvolvem 0 programa "Acessibilidade-Projeto para Todos", no intuito de eliminar as barreiras arquitetônicas e ambientais que impedem o direito de locomoção das pessoas deficientes ${ }^{6}$.

A legislação assegura o direito de acesso, circulação e utilização dos espaços públicos pelos portadores de deficiência e pelas pessoas com mobilidade reduzida ${ }^{7}$. Dá prioridade ao atendimento dos portadores de deficiências de qualquer tipo e de idosos em repartições públicas e outros locais e estabelece normas gerais e critérios básicos para a promoção da acessibilidade das pessoas portadoras de deficiência ou com mobilidade reduzida. Prima por assegurar as condições de acessibilidade arquitetônicas, urbanísticas, de transportes, de comunicação e informação $0^{7,8}$.

Com vistas à efetivação desse direito, estabelece critérios para a adaptação das áreas de uso comum das edificações e fixa as condições exigíveis, bem como 
os padrões e as medidas que visam propiciar às pessoas melhores e mais adequadas condições de acesso aos edifícios de uso público e às vias públicas urbanas. Conforme definido, todos os projetos dirigidos a deficientes devem seguir a NBR 9050, que padroniza as construções destinadas a este público8.

Como cidadãos, todos devem contribuir para melhorar a condição de vida dessas pessoas. Nesse sentido, a reflexão sobre a necessidade de estas pessoas usufruírem dos serviços oferecidos pelo sistema básico de saúde é uma forma de contribuição e exigiu esforço consciente voltado a perceber as barreiras arquitetônicas que comprometem o acesso e a mobilidade dos portadores de deficiência física a tais unidades 9 .

Ao tratar o assunto, o projeto Acessibilidade da Pessoa Portadora de Deficiência Física e/ou Sensorial aos Serviços de Saúde: um estudo das condições físicas e de comunicação, financiado pelo Ministério da Saúde, teve por meta avaliar as condições de acessibilidade dos portadores de necessidades especiais a serviços básicos de saúde e hospitais em uma cidade de médio porte e uma metrópole ${ }^{10}$. A finalidade deste relatório é descrever o acesso físico a unidades básicas de saúde.

Por reconhecer os direitos legítimos e legais de acessibilidade e integração social dos portadores de limitação física, o estudo ora desenvolvido objetiva contribuir para o mapeamento das barreiras arquitetônicas que dificultam a acessibilidade dessas pessoas, incluindo idosos, crianças, deficientes físicos e gestantes aos serviços básicos de saúde. Esperase contribuir para a assistência e ensino no campo da enfermagem e áreas das ciências da saúde e humanas, inclusive para o campo da engenharia, arquitetura e do paisagismo.

Desse modo, o objetivo deste estudo é mapear as condições arquitetônicas de acesso do portador de limitação física aos serviços básicos de saúde, segundo a NBR 9050 da Associação Brasileira de Normas Técnicas (ABNT), de um município de médio porte do Ceará.

\section{METODOLOGIA}

A realidade em estudo é a acessibilidade da pessoa portadora de deficiência física aos serviços de saúde, sendo a pesquisa do tipo exploratório-descritivo com abordagem quantitativa ${ }^{11}$. 0 estudo exploratório e descritivo permite compreender determinada realidade e fornece subsídios para a intervenção ${ }^{12}$. Quanto ao universo deste estudo, ele é constituído por Serviços Básicos de Saúde. A amostra geográfica intencional foi constituída por uma cidade de médio porte do Ceará, a qual ocupa uma área de 2.129 quilômetros quadrados e tem uma população, estimada pelo IBGE para o ano de 1998, de 143.762 habitantes $^{13}$. $\mathrm{Na}$ época da coleta, havia na cidade 35 equipes do Programa de Saúde da Família. Em equipes do PSF, de acordo com uma lista do Ministério da Saúde, esta é a terceira do Brasil e atende $100 \%$ da população.

Em obediência aos critérios de representatividade estatística, foram sorteadas 12 Unidades Básicas de Saúde do município, ou seja, um terço do total de unidades existentes. Não se consideraram, porém, os serviços oferecidos por ambulatórios especializados.

A coleta de dados realizou-se entre agosto e setembro de 2003, com formulário do tipo cheque-lista, elaborado a partir da NBR 9050 da Associação Brasileira de Normas Técnicas ${ }^{8}$, discriminando as condições ideais de acesso estabelecidas na lei para permitir a mobilidade das pessoas portadoras de deficiência física nos serviços selecionados. 0 instrumento constou de dados de identificação da unidade e condições de acesso da pessoa com deficiência física às unidades básicas de saúde quanto à via pública, o acesso ao prédio e seu interior e a circulação vertical; o acesso por rampas, escadas e elevadores; a localização e espaços como salas e auditórios; características dos mobiliários e instalações sanitárias. Como material de apoio, utilizaram-se uma fita métrica e máquina fotográfica digital.

A análise dos dados tem abordagem quantitativa, após agrupamentos em variáveis do tipo estruturas arquitetônicas, móveis, equipamentos, sinalização, entre outras. Segundo apontado, a freqüência de ocorrências dificulta 0 acesso do portador de deficiência física. Como referencial teórico adotado, sobressaem os preceitos da ABNT ${ }^{8}$.

A investigação respeitou os princípios bioéticos postulados na Resolução 196/96 do Conselho Nacional da Saúde, e foi aprovada pelo Comitê de Ética do Hospital Universitário Walter Cantídio ${ }^{14}$. Antes de se dar início à coleta de dados, o projeto foi apresentado ao Secretário de Saúde do Município e desenvolvido após autorização formal por parte dele. No momento da coleta de dados, foi solicitado verbalmente 0 consentimento livre e esclarecido do gerente responsável por cada unidade.

\section{APRESENTAÇÃO DOS RESULTADOS}

Esta seção apresenta os resultados obtidos por meio do mapeamento da área física, englobando os diversos aspectos da via pública, acesso ao prédio e circulação no seu interior, adequação de equipamentos, mobiliários, salas e auditórios das unidades básicas de saúde do município, conforme os padrões técnicos 
testados e estabelecidos na NBR 9050, da ABNT, que assegura o direito de acesso, circulação e utilização de espaços públicos e privados por pessoas portadoras de deficiências ou com mobilidade reduzida ${ }^{8}$.

De acordo com o Gráfico 1, dos 12 locais avaliados, nenhum possuía calçadas livres de buracos e desnivelamentos. Desníveis presentes no solo de ruas e avenidas adjacentes aos estabelecimentos de saúde, na maior parte dos locais (10), também dificultavam o tráfego de portadores de limitação física. A primeira barreira a ser eliminada são os desníveis no solo acima de $1,50 \mathrm{~cm}$ (altura máxima que uma cadeira de rodas

GRÁFICO 1: Mapeamento das vias públicas circunvizinhas às 12 unidades básicas de saúde. (Município do Ceará, agosto-setembro/2003)

Via pública

1. Faixas para pedestres;

2. Rebaixamento de meio fio;

3. Obras protegidas por tapume;

4. Calçadas livres de obstáculos;

5. Avenidas livres de buracos;

6. Calçadas livres de desnivelamentos;

7. Calçadas com largura de 1,50 metros;

8. Sinalizações de trânsito;

9. Sinalização do percurso para a instituição de saúde;

10. Semáforos estratégicos com botoeiras de comando;

11. Semáforos de avenidas com sinalização visual e auditiva.

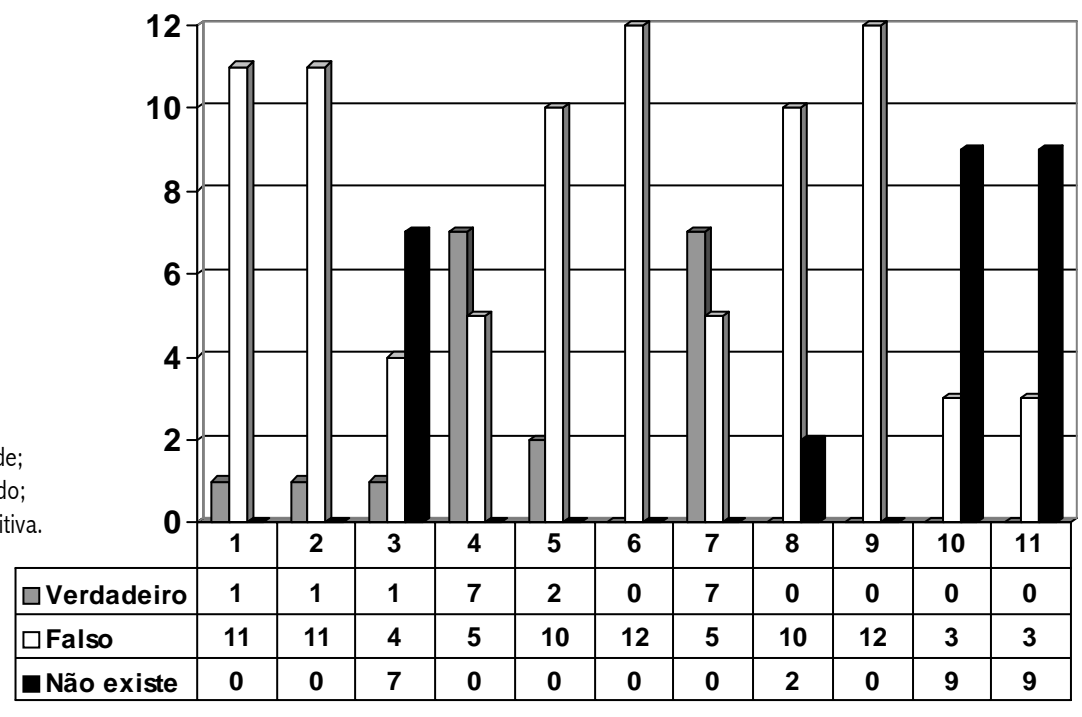

consegue transpor), tanto nas adjacências quanto nas entradas e no interior dos estabelecimentos ${ }^{8}$. Em contrapartida, a maioria das calçadas (7) estava livre de obstáculos, tais como cadeiras de bar ou qualquer outro tipo de mobiliário que imperia ou dificultaria o trânsito de pessoas deficientes, e possuía largura mínima de 1,50 metro, de modo a promover o livre trânsito de cadeiristas, conforme a norma.
Outro ponto que deixou a desejar foi a sinalização. Em nove dos 12 locais visitados não havia semáforos . Além disso, apenas um local possuía faixa destinada à passagem de pedestres.

Como mostra o Gráfico 2, do total das unidades avaliadas (12), nenhuma dispunha de estacionamento privativo devidamente demarcado com o Símbolo Internacional de Acesso e corredores de circulação com

GRÁFICO 2: Mapeamento das vias públicas circunvizinhas às 12 unidades básicas de saúde e dados referentes à acessibilidade ao interior das unidades. (Município do Ceará, agosto-setembro/2003).

Acesso ao prédio e ao interior do prédio

1. Via pública com rebaixamento de guias;

2. Estacionamento para PD demarcado;

3. Corredores de circulação com indicativo para deslocamento;

4. Percurso livre de obstáculos;

5. Escadaria com corrimão;

6. Rampa de acesso para PD;

7. Porta com largura de $80 \mathrm{~cm}$;

8. Porta vai-e-vem com visor vertical;

9. Porta de correr com trilhos rebaixados;

10. Piso de superfície regular, estável, firme e antiderrapante;

11. Área de circulação com, no mínimo, 1,20m de largura.

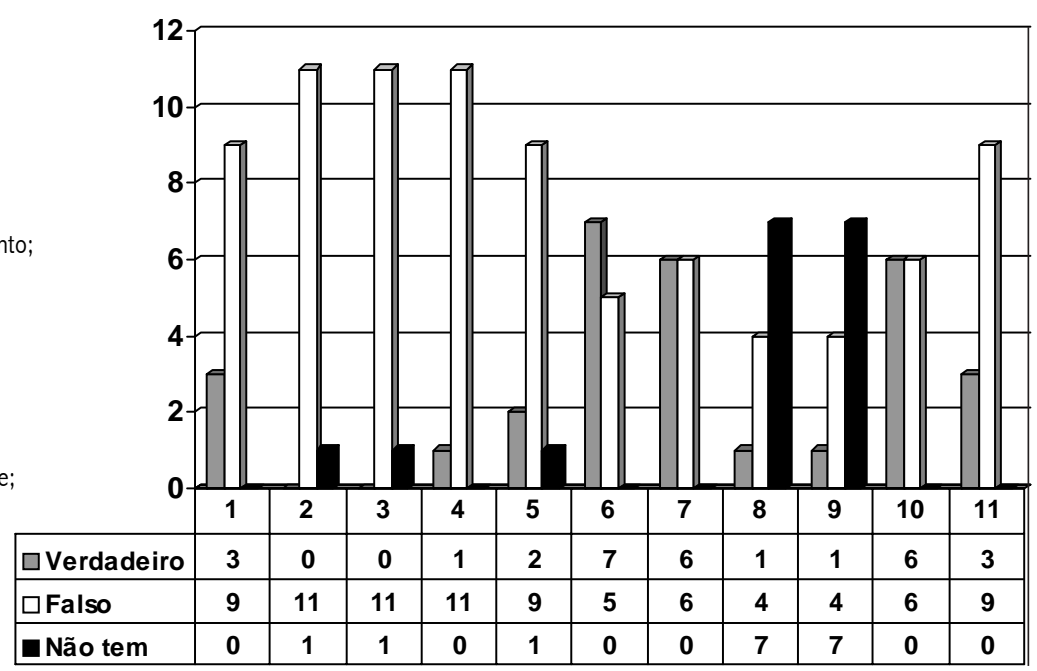


indicativo para deslocamento. Em estacionamentos com até 100 vagas, devem existir duas vagas reservadas a deficientes; naqueles com mais de 100 vagas, deve haver $1 \%$ destas destinado a essas pessoas 8 .

Três locais possuíam rebaixamento de guias por todo o trajeto; apenas um apresentou percurso livre de obstáculos, tipo lixeiras, bebedouros, mobiliários, jarros de plantas e outros objetos que dificultem a passagem das pessoas usuárias de cadeiras de rodas ou muletas.

No referente ao acesso ao interior do prédio, conforme mostra o Gráfico 2, as escadas, na maioria dos locais (10), não tinham corrimãos; entretanto, a maioria (7) apresentou rampas de acesso. Dos cinco locais onde havia portas do tipo vai-e-vem ou de duas folhas, apenas um possuía visor vertical. Conforme determinado, as portas de correr devem possuir trilhos nivelados ao chão, a fim de permitir o livre tráfego de cadeiras de rodas e 0 trânsito de deficientes visuais. Dos cinco locais encontrados com esse tipo de entrada, apenas um atendia a essa norma.

Quanto aos pisos, os polidos podem causar quedas e acidentes. 0 ideal é o uso de pisos antiderrapantes e com superfícies regulares, firmes, contínuas e estáveis. Tal item foi contemplado em metade dos casos. Vale ressaltar, ainda, que as áreas de circulação coletiva devem ter, no mínimo, 1,20 m de largura, para facilitar o livre tráfego de cadeiristas ${ }^{8}$. Dos 12 locais avaliados, nove não atendiam a essas exigências.

Os acessos às unidades de saúde estão relacionados diretamente com a circulação de sua população usuária e de materiais. A relação a ser considerada é do tipo funcional, e não de número. 0 acesso de pessoas, entre elas pacientes, acompanhantes, funcionários e alunos, deve possibilitar a entrada dos portadores de limitação física ao prédio sem a ajuda de terceiros, ou seja, com total autonomia.

Como mostrado no Gráfico 3, o mobiliário, a exemplo de balcões, salas e auditórios, está longe do ideal preconizado para atender às necessidades dessa clientela. Segundo recomendado, os balcões de trabalho devem ter, na sua parte superior, a altura de $80 \mathrm{~cm}$ do piso, o que possibilita uma boa troca de informações entre o usuário de cadeira de rodas e 0 atendente. Em nove locais, tais condições foram consideradas inadequadas.

Em cinco locais, dos nove que possuíam telefones públicos, os aparelhos se encontravam a uma altura adequada. Dos 11 que possuíam bebedouros, nenhum atendia às medidas antropométricas adequadas, sendo encontradas alturas superiores e inferiores à preconizada pela NRB $9050^{8}$. Além disso, os locais de reunião não possuíam, em sua maioria (9), espaços destinados, especificamente, aos deficientes usuários de cadeiras de rodas. Entretanto, na maioria das unidades (9), estes usuários dispunham de espaço suficiente para inserir uma cadeira, já que o mobiliário encontrado em tais salas era do tipo móvel.

De acordo com o exposto no Gráfico 4, das 12 unidades de saúde visitadas, apenas três possuíam banheiro destinado aos deficientes físicos; quatro tinham sinalização indicando a localização das instalações sanitárias, e a metade disponibilizava banheiro para cada sexo.

0 usuário de cadeira de rodas necessita de áreas de rotação ao longo de todo o percurso da rota

GRÁFICO 3: Mapeamento do mobiliário e avaliação da localização de espaços e assentos em salas/auditórios em 12 unidades básicas de saúde. (Município do Ceará, agosto-setembro/2003)

Equipamentos/ mobiliário/ salas e auditórios

1. Balcões com altura de $80 \mathrm{~cm}$ do piso;

2. Mesas de trabalho com altura de $80 \mathrm{~cm}$ do piso;

3. Acentos com $45 \mathrm{~cm}$ de profundidade e $46 \mathrm{~cm}$ de altura do piso;

4. Bebedouros a $80 \mathrm{~cm}$ do piso;

5. Telefones a $80 \mathrm{~cm}$ do piso;

6. Botoeiras entre $80 \mathrm{~cm}$ e $1,20 \mathrm{~m}$ do piso;

7. Locais de reunião com espaço para cadeiras de rodas;

8. Acentos com espaço livre frontal de $60 \mathrm{~cm}$;

9. Conforto, segurança, boa visibilidade e acústica;

10. Integrados com a disposição geral dos assentos;

11. Não obstruindo os demais assentos e a circulação;

12. Localizados próximos à circulação de emergência.

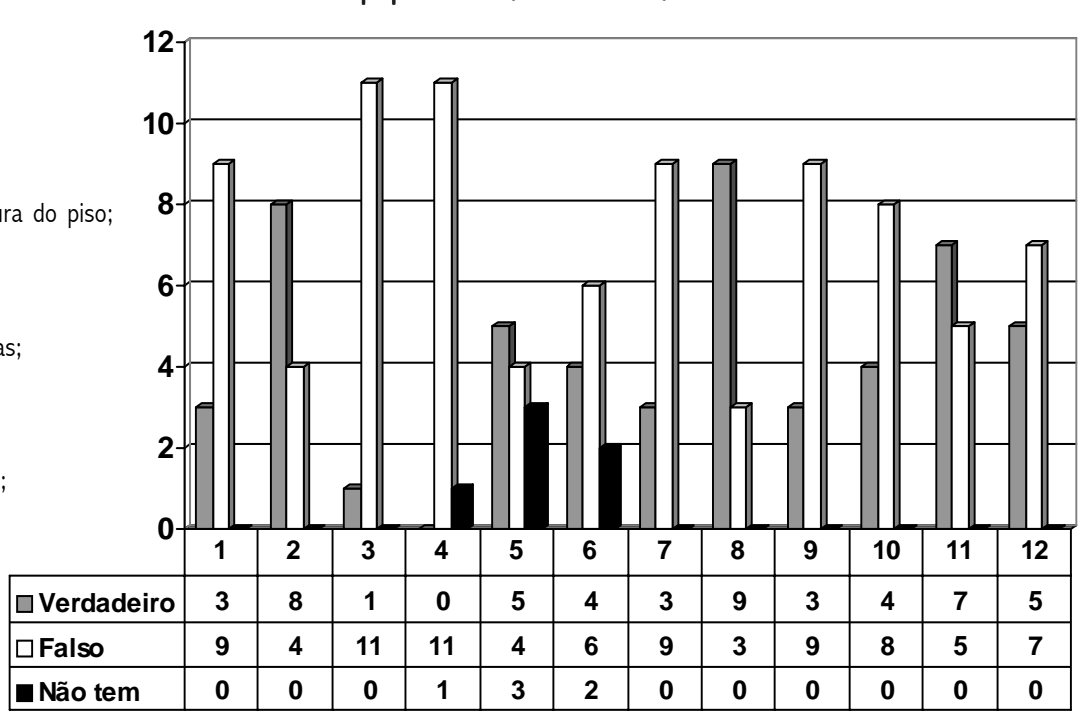


GRÁFICO 4: Aspectos gerais, área de manobra e de aproximação da bacia sanitária e dos lavatórios em 12 unidades básicas de saúde. (Município do Ceará agosto-setembro/2003).

1. Sanitários e vestiários adequados para deficientes, próximo a circulação principal;

2. Sanitários e vestiários sinalizados;

3. Sanitários e vestiários disponíveis para ambos os sexos;

4. Área de manobra de, no mínimo $1,20 \mathrm{~m}$ por $1,20 \mathrm{~m}$ para rotação de $90^{\circ}$

5. Espaço livre de $1,10 \mathrm{~m}$ por $80 \mathrm{~cm}$ para transposição;

6. Parede lateral e de fundo com barras horizontais;

7. Barras horizontais com comprimento de $90 \mathrm{~cm}$;

8. Barras horizontais a $76 \mathrm{~cm}$ do piso;

9. Bacia sanitária a $46 \mathrm{~cm}$ do piso;

10. Papeleira a $40 \mathrm{~cm}$ do piso e $15 \mathrm{~cm}$ da extremidade frontal;

11. Válvula de descarga a $1,00 \mathrm{~m}$ do piso;

12. Válvula de descarga funciona com leve pressão;

13. Lavatório do tipo sem coluna;

Instalações sanitárias

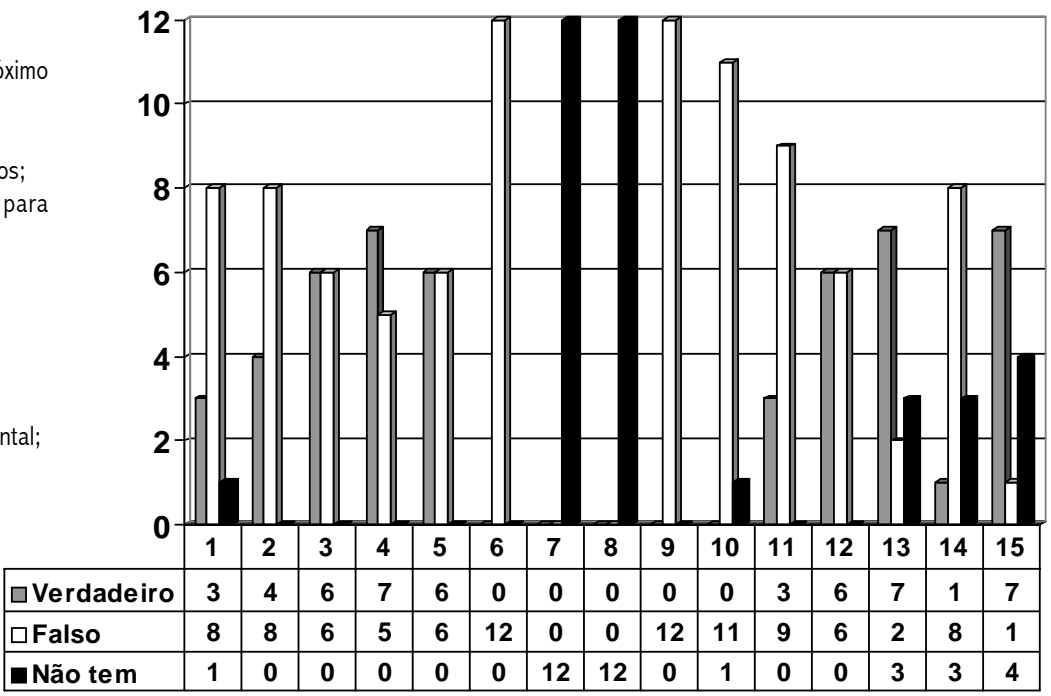

acessível. Em áreas confinadas, tais como banheiros, devem ser previstos $1,20 \mathrm{~m} \times 1,20 \mathrm{~m}$, para rotações de $90^{\circ} ; 1,20 \mathrm{~m} \times 1,50 \mathrm{~m}$, para rotações de $180^{\circ} ; 1,50$ $\mathrm{m} \times 1,50 \mathrm{~m}$, para rotações de $360^{\circ}$. Dos 12 locais visitados, sete permitiam ao deficiente físico uma rotação de no mínimo $90^{\circ}$.

Nos banheiros, a área de transferência é aquela que torna possivel a transposição da cadeira de rodas para a peça sanitária. Neste local, a área de aproximação deve oferecer espaço livre para o uso da peça, sem transposição. Tais áreas devem ter um mínimo de 1,10 m por 0,80 m, podendo estar dispostas frontal ou lateralmente à peça ${ }^{8}$. Metade dos locais avaliados apresentou uma área de transposição adequada, como mostra o Gráfico 4.

A fim de facilitar a transposição do usuário de cadeira de rodas à bacia sanitária e minimizar o risco de quedas para aqueles com mobilidade reduzida, devem ser instaladas barras horizontais para apoio e auxílio ${ }^{8}$. Nenhuma unidade oferecia esse acessório em seus banheiros. Além disso, foram encontradas bacias sanitárias (12), papeleiras (11), dispositivos de descarga (9) e lavatórios (8) a uma altura superior à preconizada.

Quanto aos lavatórios, devem ser do tipo sem coluna, para permitir a aproximação de pessoas em cadeiras de rodas ${ }^{8}$. Dos nove banheiros avaliados, que possuíam lavatórios, sete eram desse tipo. Ainda conforme determinado, as torneiras devem ter alavancas operáveis com um único movimento, ou seja, de monocomando. Tal item foi observado em sete dos oito banheiros que possuíam torneiras.

Como se vê, a legislação brasileira apresenta regras claras para a inclusão das pessoas com limitação física.
Sua aplicação, porém, enfrenta barreiras decorrentes de preconceitos e dúvidas sobre a capacidade de essas pessoas serem independentes. É preciso, pois, fazer cumprir as determinações a esse respeito. Cabe às secretarias estaduais e municipais de saúde a responsabilidade pela aplicação e execução de ações que atendam às especificidades das deficiências existentes para o pleno atendimento no setor de saúde com políticas integradas nos três níveis de assistência.

\section{CONSIDERAÇÕES FINAIS}

0 mapeamento das vias públicas apontou para a insegurança à qual os portadores de limitação física estão expostos no caminho para as unidades básicas de saúde. Como é notório, as condições de acesso ao prédio inviabilizam o livre trânsito de pessoas em cadeira de rodas, de usuários de muletas e com mobilidade reduzida. Desse modo, a chegada desses indivíduos às unidades básicas de saúde torna-se uma tarefa quase impossível.

Para garantir a execução da legislação, 0 planejamento e urbanização das vias públicas, parques e demais espaços de uso público devem ser concebidos e executados de forma a torná-los acessíveis para as pessoas portadoras de deficiência ou mobilidade reduzida. Os sinais de tráfego, semáforos, postes de iluminação e outros elementos verticais de sinalização instalados em itinerário ou espaço de acesso para pedestres devem ser dispostos de modo a não dificultar ou impedir a circulação.

No tocante ao acesso ao prédio da unidade básica de saúde e ao seu interior, constata-se a inobservância em relação às normas descritas para o acesso de 
deficientes físicos e indivíduos com mobilidade reduzida. Os resultados refletem o descaso com essa parcela da população e denotam claramente que a arquitetura externa e interna dificulta e até impossibilita 0 acesso.

Nas unidades básicas de saúde, os auditórios e locais de reuniões são utilizados para realização de palestras educativas, atividade essencial na proposta do Sistema Único de Saúde, segundo a qual é preciso educar para prevenir, de forma integral, equânime e universal. Poucas unidades visitadas dispunham de condições ideais para a total integração das pessoas portadoras de deficiências em tais ambientes. Isto reforça a invisibilidade dessa fatia populacional diante dos gestores responsáveis por tais programações.

Em relação ao acesso às instalações sanitárias, com a condição dos sanitários encontrada, essas pessoas necessitarão da ajuda de terceiros e, desse modo, reduzirão de forma contundente sua independência. A instalação das medidas corretas promove a independência do deficiente físico; assegura-lhe intimidade e privacidade. Para o portador de deficiência física ou com mobilidade reduzida, a simples

\section{Referências}

1. Brasil. Constituição (1988). Rio de Janeiro: Senado Federal, 1989.

2. NeriM, etal. Retratos da deficiênciano Brasil. Rio de Janeiro: FGV;2003. 250p.

3. Ministério da Saúde (BR). Atenção à pessoa portadora de deficiência no Sistema Único de Saúde. Brasília, 1993.

4. Amaralian MLT, Pinto EB, Ghirardi MIG, Lichtig I, Masini EFS, Pasqualin L. Conceituando deficiência. Rev Saúde Pública, 2000 fev; 34(1): 97-103.

5. França ISX, Pagliuca LMF. Ditos e não-ditos sobre a integração social das pessoas com deficiência. Rev. RENE, Fortaleza 2002 jan/ jun; 3(1):57-66.

6. Coordenadoria Nacional para Integração da Pessoa Portadora de Deficiência - CORDE (BR). [online] [acesso 2002 jan 04] Disponível em: http://www.mj.gov.br/sndh/projetos_corde_acessibilidade.htm.

7. Brasil. Lei $n^{\circ} 10.098$, de 19 de dezembro de 2000. Estabelece normas gerais e critérios básicos para a promoção da acessibilidade das pessoas portadoras de deficiência ou com mobilidade reduzida, e dá outras providências. [online] [acesso 2003 maio 20] Disponível em:http://www.acessibilidade.org.br/Lei\%20Acessibilidade10098.htm.

8. Associação Brasileira de Normas Técnicas - NBR 9050. Acessibilidade de pessoas portadoras de deficiências a edificações, espaço, mobiliário e equipamentos urbanos.. [online] [acesso 2003 maio 20] Disponível em: http://www.aibr.com/det/sadet/acesso.htm.

9. Aragao AEA. Acessibilidade da pessoa portadora de deficiência física aos serviços hospitalares: avaliação das barreiras arquitetônicas. [dissertação] Fortaleza: Universidade Federal do Ceará; 2004. ida ao banheiro pode se tornar uma tarefa extremamente árdua e, às vezes, até impossível.

Conforme se sabe, a Constituição ${ }^{1}$ assegurou 0 acesso universal à saúde. Por conseguinte, a parcela da população que apresenta alguma limitação tem este direito garantido. Contudo, é imprescindível estabelecer as condições de deslocamento urbano e acesso às edificações e instalações ${ }^{7,8}$. A retirada de todo obstáculo à mobilidade nas edificações, vias públicas e sistemas de transportes beneficia não somente um segmento da população, mas todos os habitantes.

Esta breve análise acerca da expansão urbana, particularmente no contexto brasileiro, evidencia a ausência de planejamento que contemple a necessidade específica de todos. Assim, o modelo de cidade baseado em uma organização espacial e de atitude que impede ou dificulta 0 acesso, a liberdade de movimento, a circulação segura e a possibilidade de comunicação e informação, compromete a qualidade de vida de toda a população. De modo especial, compromete ainda mais a das pessoas portadoras de limitação física e com deficiência.

10. Pagliuca LMF, França ISX, Moura ERF, Caetano JÁ, Macedo KNF, Vasconcelos $L R$ et al. Acessibilidade da pessoa portadora de deficiência física e/ou sensorial aos serviços de saúde: estudo das condições físicas e de comunicação. Relatório de Pesquisa da Universidade Federal do Ceará. Fortaleza; 2004.

11. Gil AC. Métodos e técnicas de pesquisa social. São Paulo: Atlas; 1999.

12. Polit DF, Hugnler B. Fundamentos de pesquisa em enfermagem. Porto Alegre: Artes Médicas; 1995.

13. Instituto Brasileiro de Geografia e Estatística - IBGE. Anuário estatístico do Brasil. Rio de Janeiro, 1998.

14. Ministério da Saúde (BR). Conselho Nacional de Ética em Pesquisa - CONEP. Resolução n 196/96: sobre pesquisa envolvendo seres humanos. Brasília, 1996. 24p.

\section{Nota}

aProjeto financiado pelo Ministério da Saúde/FUNCAP

\section{Sobre as Autoras}

\section{Luciana Rodrigues Vasconcelos}

Enfermeira, ex-bolsista PIBIC. Universidade Federal do Ceará.

\section{Lorita Marlena Freitag Pagliuca}

Enfermeira. Doutora em Enfermagem, Professora Titular do DENF/ FFOE/Universidade Federal do Ceará. Pesquisadora CNPq. 